\title{
The Evaluation of Maximum Tariffs in an Emerging Economy: The Nigerian Case
}

\author{
N. P. Audu Ph.D. and T. O. Apere \\ Niger Delta University, Wilberforce Island, Bayelsa State \\ +2348036756619 Email: awudupel@gmail.com
}

Accepted: August 05, 2012 Published: September 29, 2012

Doi:10.5296/ijhrs.v2i3.2472ＵRL: http://dx.doi.org/10.5296/ijhrs.v2i3.2472

\begin{abstract}
Using the Cournot and Stackelberg theories of oligopolistic competition, the paper re-evaluate the importance of tariff ranking issue under a mixed oligopoly model with foreign competitors and asymmetric costs. We demonstrated that under Cournot theory, when the size of domestic private and foreign private firms becomes more unequally distributed, maximum-welfare tariff will exceed maximum-revenue tariff. The study also revealed that under Stackelberg theory, when the domestic government protects its domestic sector, it will levy higher maximum-welfare tariffs versus maximum-revenue tariffs. These two positions notwithstanding, when the Nigerian government decides to open its doors more for foreign competitors, it will need to levy higher maximum-revenue tariffs versus maximum-welfare tariffs. The findings of this paper remain valid whether the domestic public firm acts as a leader or a follower in the market.
\end{abstract}

\section{Introduction}

The issue of maximum-revenue tariffs versus maximum-welfare tariffs is interesting and should be noticed, because tariff revenue is an important income source of the government before building up an efficient tax system in an emerging country like Nigeria. However, the government may adjust its goal from maximum-revenue to maximum-welfare along with economic improvement and the need for fiscal reform. In a traditional tariff analysis, Johnson (1952) argued that the maximum-revenue tariff is higher than the maximum-welfare tariff because a 'large' country could change the terms of trade in order to raise its social welfare level. From the strategic trade aspect, Audu (2010), Brander and Spencer (1984) have shown that government could improve its terms of trade through tariffs in an oligopoly market and take a leading position to transfer the foreign firm's revenue to a domestic firm by using tariffs as a strategic instrument. Collie (1991) demonstrated that in a Cournot duopoly market with a linear demand function and an asymmetric constant marginal cost, the maximum-welfare tariff exceeds the maximum-revenue if the domestic and foreign firms' marginal costs are equal.

Larue and Gervais (2002) allowed an asymmetric number of domestic and foreign firms and 
showed that, if the numbers of domestic firms and foreign firms are the same, the maximum-revenue tariff is higher than the maximum-welfare tariff. Clarke and Collie (2006) found that in a Bertrand price competition model, the maximum-welfare tariff is higher than the maximum-revenue tariff when the product is highly substitutable. Wang et al (2009b) introduced market share delegation in a trade duopoly context, and demonstrated that the home government unambiguously imposes a higher maximum-welfare tariff than maximum-revenue, regardless of the form of delegation. Wang et al held that the public firm is not considered in the model setting for tariff comparisons. Early studies of mixed oligopolistic markets (De Fraja \& Delbono, 1989, 1990) are based on the framework in which a welfare-maximizing public firm competes against profit-maximizing private firms in a closed economy. But the real world, along with the wave of trade liberalization, the situation of more foreign firms entering the domestic market is prevalent.

The modelling of mixed oligopoly with foreign competitors begins with Fjell and Pal (1996) who have studied the effect of introducing foreign private firms on equilibrium price and allocation of production. Audu (2010), Pal and White (1998) explored the interactions between privatization and strategic trade policies with and without efficiency gain. Fjell and Heywood (2002) as well as Uwem (2005) examined the equilibrium effects of Stackelberg leadership by a public firm, and discussed the effect of an open market policy allowing foreign and domestic firms to compete, while Matsumura (2003) studied the endogenous timing of a mixed duopoly and showed that the public firm evolves to become the leader in the presence of foreign competition. Chao and $\mathrm{Yu}$ (2006) used Matsumura's partial privatization modelling (1998) to examine the effect of partial privatization or foreign competition on optimal-welfare tariff but without considering the domestic private firms and the maximum-revenue tariff, and found that foreign competition lowers the optimal tariff rate but partial privatization raises it. Even though the public firm acts as the market leader in emerging economies and the leader role of domestic public firm has been argued exhaustively by Fjell and Heywood (2002) and Matsumura (2003) in mixed oligopoly. Lu (2006) assessed the endogenous timing in a mixed oligopoly with both domestic and foreign private firms, and observed that the domestic public firm does not move in advance of all foreign private firms. Lu (2007) also examined endogenous timing in an international mixed oligopoly in the absence of domestic private firms, and concluded that foreign leadership is a sub-game perfect equilibrium. Wang et al (2009a) considered three types of order of moves (domestic leadership, foreign leadership and simultaneous moves) in the absence of domestic private firm, and two regimes (either the domestic firm is public or private).

Most especially, they showed the different orders of moves of firms which imply different government decisions on optimal tariffs, and on whether or not to privatize the public firm. Therefore, whether the firms make decisions sequentially or simultaneously is of vital importance. In this paper, we assessed the priority of the maximum-revenue tariff and the maximum-welfare tariff under a mixed oligopoly model with foreign competitors and asymmetrical costs. The paper showed that under Cournot competition, when the size of domestic private and foreign private firms becomes more unequally distributed, maximum-welfare tariffs will exceed maximum-revenue tariffs. We also show that under Stackelberg competition, when the domestic government protects its domestic sector, it will 
levy higher maximum-welfare tariffs versus maximum-revenue tariffs; however, when it decides to open its doors more for foreign competitors, it will need to levy higher maximum-revenue tariffs versus maximum-welfare tariffs. The above results remain valid whether the domestic public firms acts as a leader or a follower. This paper is divided into five sections. Section I is the introduction, Section II focuses on theoretical underpinning and modelling while section III deals with the tariff ranking under different order of moves between public and private firms. Section IV we examines the effect of different objective function of the public firm and lastly, Section V summarizes the paper and conclude.

\section{I . Theoretical underpinning and Modelling}

Consider a domestic market for a homogeneous good produced by one public firm, $m$ domestic private firms and $n$ foreign private firms. The linear demand function is $P=\alpha-Q$.

The supply equation is given by $Q=Q_{s}+\sum_{i=1}^{m} Q_{i}+\sum_{j=1}^{n} Q_{j}$

Where $\mathrm{Q}_{s}, \mathrm{Q}_{i}$ and $\mathrm{Q}_{j}$ denotes respectively, domestic public firm's, domestic private firm's and foreign private firm's production. The marginal costs for the public firm, the domestic private firms and foreign private firms are $c s, c i$ and $c j$, respectively. We assume that $C_{s}>\mathrm{C}_{i}>\mathrm{C}_{j}>0$, which means the production efficiency of public firm is lower than that of domestic private firms, and the production efficiency of domestic private firms is lower than that of foreign private firms, too. The domestic government imposes a specific tariff on the foreign firm and the tariff rate is $t$, so the tariff revenue is $R=t \sum_{j=1}^{n} Q_{j}$

While the social welfare would be defined as, $W=C S+\pi_{S}+\sum_{i=1}^{m} \pi_{i}+t \sum_{j}^{n} Q_{j}$

where the consumer surplus is given by $C S=\frac{1}{2}\left(Q_{s}+\sum_{i=1}^{m} Q_{i}+\sum_{j}^{n} Q_{j}\right)^{2}$

But the profits of public firm, domestic private firms and foreign private firms are given by:

$$
\begin{aligned}
\pi_{s} & =\left(P-\mathrm{C}_{s}\right) \mathrm{Q}_{s} \\
\pi_{i} & =\left(P-\mathrm{C}_{i}\right) \mathrm{Q}_{i} \\
\pi_{j} & =\left(P-\mathrm{C}_{j}-t\right) \mathrm{Q}_{j}
\end{aligned} .
$$

In this model, backward induction is used to solve the sub-game perfect Nash equilibrium.

\section{Tariff ranking under different order of moves between public and private firms}

In section 3, the cases of Cournot competition, Stackelberg public leader and follower are evaluated under mixed oligopoly in order to see whether the order of firm's move influences the ranking of maximum-welfare tariff and maximum-revenue tariff.

\section{a) Cournot competition}

Further analysis of Cournot shows that the $(m+n)$ private firms maximize their profits, and 
the public firm maximizes social welfare, where $\frac{\partial \pi_{i}}{\partial Q_{i}}=0, \frac{\partial \pi_{j}}{\partial Q_{j}}=0$ and $\frac{\partial W}{\partial Q_{s}}=0$.

From the first-order conditions, we derive the thus:

$$
\left.\begin{array}{l}
Q_{s}^{*}(t)=a-C_{s}-\frac{m\left[\left(C_{s}-C_{i}\right)-n\left(C-C_{j}\right)+m t\right]}{1+n} \\
Q_{s}^{*}(t)=\frac{\left(C_{s}-C_{i}\right)-n\left(C_{i}-C_{j}\right)+m t}{1+n} \\
Q_{s}^{*}(t)=\frac{C_{s}-C_{j}-t}{1+n}
\end{array}\right\} . . .
$$

From equation (6), it can be seen that when $m>0$, and $C_{s}<$ $\hat{C}_{s} \equiv \frac{(1+n) a+m\left[\left(C_{i}+n\left(C_{i}-C_{j}-t\right)\right]\right.}{1+m+n}, \mathrm{Q}_{s}$ is positive. In addition, when $t \geq C_{s}-C_{j}, Q_{j}=0$, and $\dot{\mathrm{t}}_{C}=C_{s}-C_{j}$ is the prohibitive tariff rate. In the first stage, the domestic government maximizes social welfare or tariff revenue. If the domestic government maximizes social welfare then we obtain

$$
\begin{aligned}
& \frac{\delta W}{\delta t}=Q\left[\frac{\delta Q_{s}}{\delta t}+m \frac{\delta Q_{i}}{\delta t}+n \frac{\delta Q_{j}}{\delta t}\right]+\left[Q_{s} \frac{\delta P}{\delta t}+\left(P-C_{s}\right) \frac{\delta Q_{s}}{\delta t}\right]+m\left[Q_{i} \frac{\delta P}{\delta t}+\left(P-C_{s}\right) \frac{\delta Q_{i}}{\delta t}\right]+ \\
& n\left[Q_{j}+t \frac{\delta Q_{j}}{\delta t}\right]
\end{aligned}
$$

The first term is the consumer surplus effect, if it is negative, then it means increasing tariff will decrease consumer surplus. Because $m Q_{i}^{*}+Q_{s}^{*}=a-C_{s}$, the total output of public firm and domestic private firms will be constant and not affected by $n$ and $t$, so in the first term, $\frac{\delta Q_{s}}{\delta t}+m \frac{\delta Q_{i}}{\delta t}=0$; the consumer surplus effect is negative. The second and third terms denote the profit shifting effect. The public firm may continue to produce until its profit becomes negative (when $n=0, P<0$ ), and the impact of tariff on its profit is ambiguous. The sign of the third term is positive which is simply because tariff raises the marginal cost of foreign firms resulting in the profit shift to domestic private firms. The fourth term is the revenue effect which could either be positive or negative depending on the relative magnitude of consumer surplus effect and the profit shifting effect. Hence, when the sum of consumer surplus effect and the profit shifting effect is positive, and the fourth term is negative, the maximum-welfare tariff exceeds the maximum-revenue tariff. Note that when $n=0$, tariff has negative impact on the public firm's profit in the second term, and the third term is zero, so the profit shift to domestic firms is negative, but the revenue effect must be positive. Accordingly, the maximum-revenue tariff is higher than the maximum-welfare tariff. From 
the first-order condition of equation (6), we have $t_{w}^{*}=\frac{\left(C_{s}-c_{j}\right)+(1+n) m\left(C_{s}-C_{i}\right)}{2+n}$. When $n$

$\leq 1, t_{w}^{*}<t_{c}$; otherwise, when $m>0$, it depends on the relative costs between domestic public firm, local private and foreign private firms.

Lemma theory. When $m<\frac{\left(C_{s}-C_{j}\right)}{\left(C_{s}-C_{i}\right)}, \quad t_{w}^{*}-\dot{t}_{c}<0$ and $t_{C W}^{*}=\frac{\left(C_{s}-C_{j}\right)+(1+n) m\left(C_{s}-C_{i}\right)}{2+n}$; if $m \geq \frac{\left(C_{s}-C_{j}\right)}{\left(C_{s}-C_{i}\right)}, \quad t_{w}^{*}-\dot{t}_{c} \geq 0$ and $t_{w}^{*}=\left(C_{s}-C_{j}\right)$.

Proof: Subtracting $\dot{t}_{c}=C_{s}-C_{j}$ from $t_{w}^{*}$,

$$
\begin{aligned}
t_{w}^{*}-\dot{t}_{c}=\frac{\left(C_{s}-C_{j}\right)+(1+n) m\left(C_{s}-C_{i}\right)}{2+n}-\left(C_{s}-C_{j}\right)<0 \\
\Leftrightarrow\left(C_{s}-C_{j}\right)+(1+n) m\left(C_{s}-C_{i}\right)<(2+n)\left(C_{s}-C_{j}\right) \\
\Leftrightarrow(1+n) m\left(C_{s}-C_{i}\right)<(1+n)\left(C_{s}-C_{j}\right) \\
\Leftrightarrow m\left(C_{s}-C_{j}\right)<\left(C_{s}-C_{j}\right) \\
\Leftrightarrow m \frac{\left(C_{s}-C_{j}\right)}{\left(C_{s}-C_{i}\right)}
\end{aligned}
$$

Since $C_{i}>C_{j}$ and $C_{s}-C_{i}<C_{s}-C_{j}, \quad \frac{\left(C_{s}-C_{j}\right)}{\left(C_{s}-C_{i}\right)}>1$. Hence, when $m \leq 1, t_{w}^{*}-\dot{t}_{c}<0$ and $t_{C W}^{*}=\frac{\left(C_{s}-C_{j}\right)+(1+n) m\left(C_{s}-C_{i}\right)}{2+n}$. From Lemma 1, we have $t_{C W}^{*}=\frac{\left(C_{s}-C_{j}\right)+(1+n) m\left(C_{s}-C_{i}\right)}{2+n}, \frac{\left(C_{s}-C_{j}\right)}{\left(C_{s}-C_{i}\right)}>m\left(C_{s}-C_{j}\right), m \geq \frac{\left(C_{s}-C_{j}\right)}{\left(C_{s}-C_{i}\right)}$

where $C W$ denotes maximum-welfare tariff under Cournot competition. If the domestic government maximises tariff revenue, from $\frac{\delta R}{\delta t}=0$, we therefore derive equation (9) thus $t_{C R}^{*}=\frac{C_{s}-C}{2}$.

where $C R$ denotes maximum-revenue tariff under Cournot competition. From equation (8) and (9) we find that $t_{C W}^{*} \leq t^{*}{ }_{C R}$ when $\frac{\left(C_{s}-C_{j}\right)}{\left(C_{s}-C_{i}\right)} \geq A_{c} \equiv \frac{2 m(1+n)}{n}>m ; t_{C W}^{*}>t{ }_{C R}$ when 
$A_{c}>\frac{\left(C_{s}-C_{j}\right)}{\left(C_{s}-C_{i}\right)}>m ;$ Differentiate $A_{C}$ with respect to $m$ and $n, \frac{\delta A_{c}}{\delta m}=\frac{2(1+n)}{n}>0$ and $\frac{\delta A_{c}}{\delta m}=\frac{-2 m}{m^{2}}<0$. Similarly, when $m$ gets larger but $n$ becomes smaller, optimum-welfare tariff will exceed maximum-revenue tariff. We have the following proposition:

Cournot framework: Under Cournot competition with asymmetrical costs assumes that when the ratio of cost differences exceeds $A_{c}$ then maximum-welfare tariff can be lower than maximum-revenue tariff. Similarly, when ' $n$ ' gets larger but ' $m$ ' becomes smaller (i.e., when the size of domestic private and foreign private firms become more unequally distributed, maximum-welfare tariff in relative magnitude will be greater than maximum-revenue tariff as shown in appendix 1)

The intuition behind Proposition 1 is that with the domestic private and foreign firm's competition, when the domestic government imposes a tariff, the public firm will further reduce its output when the public firm's marginal cost exceeds both domestic and foreign private firm's one, and then due to that, the profit shifting effect is less than the consumer surplus loss, so the domestic government imposes a higher maximum-welfare tariff versus maximum-revenue tariff. But, in the likelihood that maximum-welfare tariff can be lower than maximum-revenue tariff if the public firm's marginal cost highly exceeds both domestic and foreign private firm's one, this proposition demonstrated that under mixed Cournot competition, the maximum-welfare tariff is greater than the maximum-revenue tariff when the public firm and private firm's marginal costs are different, which modifies and strengthens the result obtained in Collie (1991); the maximum-welfare tariff exceeds the maximum-revenue tariff if the domestic and foreign firms' marginal costs are equal.

b) Stackelberg public leader framework

Here, the $(n+m)$ private firms maximize their profits when $\frac{\delta \pi_{i}}{\delta Q_{i}}=0$ and $\frac{\delta \pi_{j}}{\delta Q_{j}}=0$. Therefore, we derive the first-order necessary condition thus

$$
\left.\begin{array}{rl}
Q_{i}^{*}(t) & =\frac{a+n t-C_{i}-n\left(C_{i}-C_{j}\right)-Q_{s}}{1+m+n} \\
Q_{j}^{*}(t) & =\frac{a-C_{j}+m\left(C_{i}-C_{j}\right)-(1+n) t-Q_{s}}{1+m+n}
\end{array}\right\}
$$

Similarly, at the point where the public firm maximizes social welfare, $\frac{\delta W}{\delta Q_{s}}=0$, and we derive equilibrium thus:

$$
Q_{j}^{*}(t)=a-C_{s}-\frac{\left[2 m+(n+m)^{2}\right]\left(C_{s}-C_{i}\right)+m n\left(C_{i}-C_{j}\right)+n(1+2 m) t}{1+2 n} .
$$

From equations (9) and (10), when $t \geq \dot{t}_{S L}, Q_{j}=0$, and $\dot{t}_{S L} \equiv m\left(C_{s}-C_{i}\right)+(1+n)\left(C_{s}-C_{j}\right)$ is the prohibitive tariff rate. Also, at the inception level, if the domestic government maximizes 
social welfare, we substitute equations (10) and (11) into equation (3), when $\frac{\delta W}{\delta Q_{s}}=0$, and

obtain $t_{S L W}^{*}=\frac{\left(C_{s}-C_{j}\right)+2 m\left(C_{s}-C_{i}\right)}{2}$

Where $S L W$ denotes maximum-welfare tariff under public leadership. Note that $t_{S L W}^{*}-t_{S L}=-\frac{(1+2 n)\left(C_{s}-C_{j}\right)}{2}<0$ and $t_{S L W}^{*}<t_{S L}$. And if the domestic government maximizes tariff revenue, substituting equations (9) and (10) into equation (2), when $\frac{\delta R}{\delta t}=0$ we derive equation (12) thus

$t_{S L R}^{*}=\frac{m\left(C_{s}-C_{i}\right)+(1+n)\left(C_{s}-C_{j}\right)}{2}$.

From where the SLR denotes maximum-revenue tariff under public leadership. Similarly, comparing equations (11) and (12), we observed that $t_{S L W}^{*}>t_{S L R}^{*}$, when $A_{S L} \equiv \frac{m}{n}>\frac{\left(C_{s}-C_{j}\right)}{\left(C_{s}-C_{i}\right)}>1 ;$ and $t_{S L W}^{*} \leq t_{S L R}^{*}$, when $A_{S L} \leq \frac{\left(C_{s}-C_{j}\right)}{\left(C_{s}-C_{i}\right)}$. When we differentiate $A_{S L}$ with respect to $m$ and $n, \frac{\delta A_{S L}}{\delta m}=\frac{1}{n}>0$ and $\frac{\delta A_{S L}}{\delta n}=\frac{-m}{n^{2}}<0$. Therefore, when $m$ gets larger but $n$ becomes smaller, maximum-welfare tariff will exceed maximum-revenue tariff. This gave birth to proposition 2:

Stackelberg public leader framework: Under Stackelberg public leader with asymmetric costs, when the numbers of domestic private and foreign private firms are the same, the maximum-revenue tariff is higher than the maximum-welfare tariff. And the maximum-revenue tariff is higher (smaller) than the maximum-welfare tariff if the number of foreign firms is relatively larger (smaller) than that of domestic private firms. This is presented appendix 2 (i.e. for proof).

Larue and Gervais (2002) showed that if the numbers of domestic firms and foreign export firms are the same, the maximum-revenue tariff is higher than the maximum-welfare tariff. We confirm their result in mixed oligopoly setting. In our mixed Stackelberg oligopoly model with the public firm acting as a leader, because of the revenue effect that results from more foreign firms, the maximum-revenue tariff is higher than the maximum-welfare tariff if the number of foreign firms exceeds domestic private firms.

c) Stackelberg public follower concept

Further analysis shows that the public firm maximizes social welfare, when $\frac{\delta W_{j}}{\delta Q_{s}}=0$. This 
gives rise to $Q_{s}^{*}=\alpha-C_{s}-m Q_{i}$

Similarly, the $(m+n)$ private firms maximize their profits only when $\frac{\delta \pi_{i}}{\delta Q_{i}}=0$ and $\frac{\delta \pi_{j}}{\delta Q_{j}}=0$

From the first-order necessary conditions, we obtain equation (14) thus:

$Q_{s}^{*}(t)=\frac{\left(C_{S}-C_{i}\right)-n\left(C_{i}-C_{j}\right)+n t}{(1+n)(1+m)} \Rightarrow \frac{C_{S}-C_{j}+t}{(1+n)}$

From equation (15), when $t \geq \dot{t}_{S F}, \mathrm{Q}_{j}=0$, and $\dot{t}_{S F} \equiv C_{s}-C_{j}$ is the prohibitive tariff rate. Therefore, in the first stage, if the domestic government maximizes social welfare by substituting equation (15) into equation (3), when $\frac{\delta W}{\delta t}=0$ we derive the following:

$t_{S F W}^{*}=\frac{(1+m)\left(C_{S}-C_{j}\right)+(1+n) m\left(C_{S}-C_{i}\right)}{(2+n)(1+m)}$

where $S F W$ denotes maximum-welfare tariff under Stackelberg public follower. Note that $t_{S F W}^{*}-\dot{t}_{S F}=-\frac{(1+n)\left[\left(C_{S}-C_{j}\right)+m\left(C_{i}-C_{j}\right)\right]}{(2+n)(1+m)}<0$. If the domestic government maximizes tariff revenue, substituting equation (15) into equation (2), when $\frac{\delta R}{\delta t}=0$, we derive equation (17) thus:

$$
t_{S F R}^{*}=\frac{\left(C_{S}-C_{j}\right)}{2)}
$$

where SFR denotes maximum-revenue tariff under Stackelberg public follower. If we compares equations (16) and (17), we observe that $t_{S F W}^{*}>t_{S F R}^{*}$ and when $A_{S F} \equiv \frac{2 m(1+n)}{n(1+m)}>\frac{\left(C_{S}-C_{j}\right)}{\left(C_{S}-C_{i}\right)}$ and $t_{S F W}^{*} \leq t_{S F R}^{*}$ when $A_{S F} \leq \frac{\left(C_{S}-C_{j}\right)}{\left(C_{S}-C_{i}\right)}$. If we differentiate $A_{S F}$ with respect to $m$ and $n, \frac{\delta A_{S F}}{\delta m}=\frac{1+n}{n(1+m)^{2}}>0$ and $\frac{\delta A_{S F}}{\delta n}=\frac{-m}{n^{2}(1+m)}<0$. But when $m$ gets larger then $n$ becomes smaller, maximum-welfare tariff will exceed maximum-revenue tariff.

Stackelberg public follower concept: Under Stackelberg public follower and asymmetric costs, when the size of domestic private and foreign private firms become more unequally 
distributed, optimum welfare tariff will exceed maximum-revenue tariff. See appendix 3 for the proof.

The intuition behind Proposition 3 is exactly the same as that presented in Proposition 2. Owing to Propositions 2 and 3, when the domestic government protects its domestic sector, it will levy higher maximum-welfare tariffs versus maximum-revenue tariffs. However, when it decides to open its doors more for foreign competitors, it will need to levy higher maximum-revenue tariffs versus maximum-welfare tariffs. The above results remain valid whether the domestic public firms acts as a leader or a follower. Comparing the ranking of $A_{c}$, $A_{S L}\left(A_{S F}\right)$ and $A_{S F}\left(A_{S L}\right)$, we have derived the following corollary.

Corollary 1: $A_{c}>A_{S L}\left(A_{S F}\right)>A_{S F}\left(A_{S L}\right)$, if $m>(<) 2 n+1$.

Proof:

(a) $A_{C}-A_{S L}=\frac{2 m(1+n)}{n}-\frac{m}{n}=\frac{m[2(1+n)-1]}{n}>0$

(b) $A_{C}-A_{S F}=\frac{2 m(1+n)}{n}-\frac{2 m(1+n)}{n(1+m)}=\frac{\left.2 m^{2}(1+n)-1\right]}{n(1+m)}>0$

(c) $A_{S L}-A_{S F}=\frac{m}{n}-\frac{2 m(1+n)}{n(1+m)}=\frac{m(m-2 m-1)}{n(1+m)}>0$, when $n>2 m+1$.

Therefore, from proof (a), (b), and (c), we have shown that $A_{c}>A_{S L}\left(A_{S F}\right)>A_{S F}\left(A_{S L}\right)$, when $n>(<) 2 m+1$.

Also, under Cournot competition, the critical value for $t_{W}>t_{R}$ is rising and the likelihood that $t_{W} \leq t_{R}$ is increasing, ceteris paribus. But in Stackelberg Public leader and follower, the critical value depends on the relative numbers of domestic private and foreign firms; when the number of domestic private firm is relatively more (less) than the foreign private firm, $A_{S L}\left(A_{S F}\right)>A_{S F}\left(A_{S L}\right)$, as such the critical value for $t_{W}>t_{R}$ is rising and the likelihood that $t_{W} \leq$ $t_{R}$ is increasing, ceteris paribus.

\section{The effect of different objective function of the public firm}

It must be noted that the authority of the public firm and the tax-collecting administration are not the same, therefore, the objective function of the public firm is most likely to diverges from the social welfare function. It is interesting and important to see whether such divergence of objective functions affects the ranking of maximum-welfare and maximum-revenue tariffs. The public firm may maximize the sum of consumer surplus, its own profit and the profits of domestic private firms, instead of maximizing the social welfare; that is,

$$
H=C S+\pi_{S}+\sum_{i=1}^{n} \pi_{i}
$$

In the preceding part, the Cournot competition, Stackelberg public leader and public follower are studied in detail. In both instances the Cournot competition and Stackelberg public 
follower is assumed $\frac{\delta Q_{j}}{\delta Q_{s}}=0$ for public firm. As such the optimal choice of public firm's output from equation (3) derives the following first-order condition, thus:

$$
\frac{\delta W}{Q_{s}}=\frac{\delta C S}{Q_{s}}+\frac{\delta \pi_{s}}{Q_{s}}+\sum_{i=1}^{m} \frac{\delta \pi_{i}}{Q_{s}}+t \sum_{j-1}^{n} \frac{\delta \pi_{j}}{Q_{s}} \neq \frac{\delta C S}{Q_{s}}+\frac{\delta \pi_{s}}{Q_{s}}+\sum_{i=1}^{m} \frac{\delta \pi_{i}}{Q_{s}}=\frac{\delta H}{\delta Q_{s}}
$$

Similarly, differentiate equation (17) with respect to $\mathrm{Q}_{s}$, we obtain

$$
\frac{\delta H}{\delta Q_{s}}=\frac{\delta C S}{Q_{s}}+\frac{\delta \pi_{s}}{Q_{s}}+\sum_{i=1}^{m} \frac{\delta \pi_{i}}{Q_{s}}
$$

Because for the public firm, the first-order condition will not be changed whether the tariff revenue is included in the objective function, the outputs of different types of the firms will not be affected. Accordingly, maximum-welfare and maximum-revenue tariffs remain the same under Cournot competition and Stackelberg public follower. However, when the public firm acts as Stackelberg leader, $\frac{\delta Q_{j}}{\delta Q_{s}} \neq 0$, and without considering tariff revenue, we have

$$
\frac{\delta W}{Q_{s}}=\frac{\delta C S}{Q_{s}}+\frac{\delta \pi_{s}}{Q_{s}}+\sum_{i=1}^{m} \frac{\delta \pi_{i}}{Q_{s}}+t \sum_{j-1}^{n} \frac{\delta \pi_{j}}{Q_{s}} \neq \frac{\delta C S}{Q_{s}}+\frac{\delta \pi_{s}}{Q_{s}}+\sum_{i=1}^{m} \frac{\delta \pi_{i}}{Q_{s}}=\frac{\delta H}{\delta Q_{s}}
$$

And for the fact that $t \sum_{j-1}^{n} \frac{\delta \pi_{j}}{Q_{s}}<0,\left.\quad Q_{s}\right|_{\text {Max.W }}>\left.Q_{s}\right|_{\text {Max.H, }}$ the maximum-welfare and maximum-revenue tariffs are computed as follows:

$$
\begin{aligned}
t_{S L W}^{H} & =\frac{\left(C_{s}-C_{j}\right)+2 m\left(C_{s}-C_{i}\right)}{2+n} \ldots \ldots . . . \\
t_{S L R}^{H} & =\frac{m\left(C_{s}-C_{i}\right)+(1+n)\left(C_{s}-C_{j}\right)}{2(1+n)} .
\end{aligned}
$$

From equations (20) and (21), we can show that both the maximum-welfare and maximum revenue tariffs under alternative objective function are decreasing relative to the welfare maximizing decision of the public firm.

Subtracting equation (20) from equation (21) we obtain the following:

$$
t_{S L W}^{H}-t_{S L R}^{H}=\frac{(2+3 n) m\left(C_{s}-C_{i}\right)+n(1+n)\left(C_{s}-C_{j}\right)}{2(1+n)(2+n)}>0 \Rightarrow \frac{(2+n) m}{n(1+n)}>\frac{\left(C_{s}-C_{j}\right)}{\left(C_{s}-C_{i}\right)}>1
$$

Comparing equations (20) and (21), we also observed that $t_{S L W}^{H}>t_{S L R}^{H}$, when $A_{S L}^{H} \equiv \frac{(2+n) m}{n(1+n)}>\frac{\left(C_{s}-C_{j}\right)}{\left(C_{s}-C_{i}\right)}>1 ;$ and $t_{S L W}^{H} \leq t_{S L R}^{H}$, when $A_{S L}^{H} \leq \frac{\left(C_{s}-C_{j}\right)}{\left(C_{s}-C_{i}\right)}$. Differentiate $A_{S L}^{H}$ 
with respect to $m$ and $n, \frac{\delta A_{S L}^{H}}{\delta m}=\frac{2-n}{n(1+n)^{2}}>0$ and $\frac{\delta A_{S L}^{H}}{\delta m}=\frac{-[2+n(4+n)] m}{n^{2}(1+n)^{2}}<0$. As such, when $m$ gets larger but $n$ becomes smaller, maximum-welfare tariff will exceed maximum-revenue tariff. Also, the critical values of maximum-welfare and maximum-revenue tariffs for different objective functions of the public firms are compared.

When we subtracting $A_{S L}^{H} \equiv \frac{(2+n) m}{n(1+n)}$ from $A_{S L} \equiv \frac{m}{n}, A_{S L} \equiv \frac{m}{n(1+n)}>0$. Then, the when the public firm maximizes equation (18), as the critical value for $t_{W}>t_{R}$ is rising and the likelihood that $t_{W} \leq t_{R}$ is increasing, all thing being equal.

\section{Summary/Conclusion}

Uwen (2005) argued that when the marginal cost of the domestic firm is higher than that of the foreign firm under a pure Cournot duopoly market, the maximum-revenue tariff may be higher than the maximum-welfare tariff. This paper re-examines this important tariff ranking issue under a linear mixed oligopoly model with foreign competitors and asymmetrical costs. We first demonstrated that under Cournot competition, when the size of domestic private and foreign private firms becomes more unequally distributed, maximum-welfare tariff will exceed maximum-revenue tariff. We then showed that when the domestic government protects its domestic sector, it will levy higher maximum-welfare tariffs versus maximum-revenue tariffs; however, when it decides to open its doors more for foreign competitors, it will need to levy higher maximum-revenue tariffs versus maximum-welfare tariffs. The above results remain valid whether the domestic public firms acts as a leader or a follower.

Because the likelihood that maximum-welfare exceeds maximum-revenue tariffs, for those transition economies aiming to adjust policy goals from maximum-revenue tariffs to optimum welfare tariffs, the tariff reduction by the importing country alone may not be able to achieve their goals. However, when the public firm maximizes the sum of consumer surplus as well as its own profit and the profits of domestic private firms instead of maximizing the social welfare, the likelihood that when the public firm acts as Stackelberg leader, maximum-revenue tariff increasingly exceeds maximum-welfare tariff, ceteris paribus. To achieve the policy goal via tariff reduction by the importing country may not be unfeasible. 


\section{References}

Audu, N. P. (2010): Finance, Investment and Economic Growth in Nigeria: An Error Correction Model, Finance and Control Compendium. Vol. 1; 85 - 107

Bárcena-Ruiz, J.C. and Garzón, M.B. (2006): Mixed Oligopoly and Environmental Policy, Spanish Economic Review, Vol. 8; 139-160.

Beladi, H. and Chao, C. C. (2006): Does Privatization Improve the Environment? Economics Letters, Vol. 93; 343-347.

Brander, J. A. and Spencer, B. J. (1984): Tariff Protection and Imperfect Competition, in H. Kierzkowski (Ed), Monopolistic Competition and International Trade, Oxford: Oxford University Press, 194-207.

Chao, C. C. and Yu, E. S. H. (2006): Partial Privatization, Foreign Competition, and Optimum Tariff, Review of International Economics, Vol. 14; 87-92.

Clarke, R. and Collie, D. R. (2006): Maximum-welfare and Maximum-revenue Tariffs under Bertrand Duopoly, Scottish Journal of Political Economy, Vol. 53; 398-408.

Collie, D. R. (1991): Optimum Welfare and Maximum Revenue Tariffs under Oligopoly, Scottish Journal of Political Economy, Vol. 38; 398-401.

De Fraja, G. and Delbono, F. (1989): Alternative Strategies of a Public Enterprise in Oligopoly, Oxford Economic Papers, Vol. 41; 302-311.

De Fraja, G. and Delbono, F. (1990): Game Theoretic Models of Mixed Oligopoly, Journal of Economic Surveys, vol. 4; 1-17.

Fjell, K. and Pal, D. (1996): 'A Mixed Oligopoly in the Presence of Foreign Private Firms', Canadian Journal of Economics, Vol. 29, 737-743.

Fjell, K. and Heywood, J. S. (2002): Public Stackelberg Leadership in a Mixed Oligopoly with Foreign Firms, Australian Economic Papers, Vol. 41; 267-281.

Huang, C. S., Lee, J. Y. and Chen, S. S. (2006): The Optimal Government Shareholding Strategy and the Cost Structure, Seoul Journal of Economics, Vol. 9; 251-273.

Johnson, H. G. (1952): Optimum Welfare and Maximum Revenue Tariffs, Review of Economic Studies, Vol. 19; 28-35.

Katsoulacos, Y. (1994): Firms' Objectives in Transition Economies, Journal of Comparative Economics, Vol. 19; 392-409.

Larue, B. and Gervais, J. P. (2002): Welfare-maximizing and Revenue-maximizing Tariffs with Few Domestic Firms, Canadian Journal of Economics, Vol. 35; 786-804.

Lu, Y. (2006): Endogenous Timing in a Mixed Oligopoly with Foreign Competitors: The Linear Demand Case, Journal of Economics, Vol. 88; 49-68.

Lu, Y. (2007): Endogenous Timing in a Mixed Oligopoly Consisting of a Single Public Firm and Foreign Competitors, Economics Bulletin, Vol. 12; $1-7$.

Matsumura, T. (1998): Partial Privatization in Mixed Duopoly, Journal of Public Economics, Vol. 70; 473-483.

Matsumura, T. (2003): Stackelberg Mixed Duopoly with a Foreign Competitor, Bulletin of Economic Research, Vol. 55; 275-287.

Matsushima, N. and Matsumura, T. (2006): Mixed Oligopoly, Foreign Firms, and Location Choice, Regional Science and Urban Economics, Vol. 36; 753-772.

Pal, D. and White, M. D. (1998): Mixed Oligopoly, Privatization, and Strategic Trade Policy, 
Southern Economic Journal, Vol. 65; 264-281.

Uwem, E. (2005): Lecture Notes on Microeconomics Theory. Calabar: Saesprint Publihers

Wang, L. F. S. and Wang, J. (2009): Environmental Taxes in a Differentiated Mixed Duopoly', Economic Systems, Vol. 33; 389-396.

Wang, L. F. S., Wang, Y. C. and Zhao, L. (2009a): Privatization and Efficiency Gain in an International Mixed Oligopoly with Asymmetric Costs, Japanese Economic Review, Vol. 60; 539-559.

Wang, L. F. S., Wang, Y. C. and Zhao, L. (2009b): Market Share Delegation and Strategic

Trade Policy, Journal of Industry, Competition and Trade, Vol. 9; 49-56.

\section{Appendix 1}

Maximum-welfare and maximum-revenue tariffs under Cournot competition Proof of oproposition 1:

When $\frac{2(1+n) m}{n}>\frac{\left(C_{s}-C_{j}\right)}{\left(C_{s}-C_{i}\right)}, t_{C W}^{*}>t_{C R}^{*} ;$ if $\frac{2(1+n) m}{n} \leq \frac{\left(C_{s}-C_{j}\right)}{\left(C_{s}-C_{i}\right)}, t_{C W}^{*} \leq t_{C R}^{*} 2(1+)>$

When we subtracting $t_{C R}^{*}=\frac{\left(C_{s}-C\right)}{2}$ from $t_{C W}^{*}=\frac{\left(C_{s}-C_{j}\right)+(1+n) m\left(C_{s}-C_{j}\right)}{2+n}$

$$
\begin{aligned}
t_{C W}^{*}-t_{C R}^{*} & =\frac{\left(C_{s}-C_{j}\right)+(1+n) m\left(C_{s}-C_{i}\right)}{(2+n)}-\frac{\left(C_{s}-C_{i}\right)}{2} \Rightarrow \frac{2(1+n) m\left(C_{s}-C_{i}\right)-n\left(C_{s}-C_{j}\right)}{2(2+n)}>0 \\
& \Rightarrow 2(1+n) m\left(C_{s}-C_{i}\right)-m\left(C_{s}-C_{j}\right)>0 \quad \Rightarrow \frac{2(1+n) m}{n}>\frac{\left(C_{s}-C_{j}\right)}{\left(C_{s}-C_{i}\right)}
\end{aligned}
$$

\section{Appendix 2}

Maximum-welfare and maximum-revenue tariffs under Stackelberg public leader Proof of proposition 2:

When $\frac{m}{n}>\frac{\left(C_{s}-C_{j}\right)}{\left(C_{s}-C_{i}\right)}, t_{S L W}^{*}>t_{S L R}^{*}$; if $\frac{m}{n} \leq \frac{\left(C_{s}-C_{j}\right)}{\left(C_{s}-C_{i}\right)}, t_{S L W}^{*} \leq t_{S L R}^{*}$. When we substract

$$
\begin{array}{rlr}
t_{S L R}^{*} \quad=\frac{m\left(C_{s}-C_{i}\right)+(1+n)\left(C_{s}-C_{j}\right)}{2} & & \text { from } t_{S L W}^{*}=\frac{\left(C_{s}-C_{j}\right)+2 m\left(C_{s}-C_{i}\right)}{2}, \\
t_{S L W}^{*}-t_{S L R}^{*}=\frac{m\left(C_{s}-C_{i}\right)+n\left(C_{s}-C_{j}\right)}{2}>0 \quad & \Rightarrow n\left(C_{s}-C_{s}\right)-n\left(C_{s}-C_{j}\right) \\
& \Rightarrow \quad \frac{m}{n}>\frac{\left(C_{s}-C_{j}\right)}{\left(C_{s}-C_{i}\right)}>0
\end{array}
$$




\section{Appendix 3}

Maximum-welfare and maximum-revenue tariffs under Stackelberg public follower Proof of proposition 3:

When

$$
\begin{aligned}
& \frac{2 m(1+n)}{n(1+m)}>\frac{\left(C_{s}-C_{j}\right)}{\left(C_{s}-C_{i}\right)}, t_{S F W}^{*}>t_{S F R}^{*} ; \text { if } \frac{2 m(1+n)}{n(1+m)} \leq \frac{\left(C_{s}-C_{j}\right)}{\left(C_{s}-C_{i}\right)}, t_{S F W}^{*} \leq t_{S F R}^{*} \text {. However, when we } \\
& \text { substract } t_{S F R}^{*}=\frac{(1+n)\left(C_{s}-C_{j}\right)+(1+n) m\left(C_{s}-C_{i}\right)}{(2+n)(1+m)} \\
& \Rightarrow t_{S F W}^{*}-t_{S F R}^{*}=\frac{2 m(1+n)\left(C_{s}-C_{i}\right)+n(1+m)\left(C_{s}-C_{j}\right)}{2(2+n)(1+m)}>0 \\
& \Rightarrow 2 m(1+n)\left(C_{s}-C_{i}\right)+n(1+m)\left(C_{s}-C_{j}\right)>0 \quad \Rightarrow \quad \frac{2 m(1+n)}{n(1+m)}>\frac{\left(C_{s}-C_{j}\right)}{\left(C_{s}-C_{i}\right)}
\end{aligned}
$$

